Check for updates

\section{The BMJ}

Cite this as: $B M J 2020 ; 370: m 3518$ http://dx.doi.org/10.1136/bmj.m3518 Published: 09 September 2020

\section{Covid-19: England restricts gatherings to groups of six as cases rise}

\section{Elisabeth Mahase}

People in England can only gather in groups of up to six, with groups of up to 30 only allowed for work, weddings, funerals, and organised sports, the UK government has announced.

The new rules, which come into force on 14 September, were introduced after new covid-19 cases in England rose to over 2500 a day between 6 and 7 September, an increase from just over 1400 new daily cases the previous week (30 August).

Deputy chief medical officer Jonathan Van-Tam said that people had relaxed too much and they now needed to "re-engage and realise this is a continuing threat."

An Ipsos MORI survey commissioned by the Health Foundation found, however, that more than half (54\%) of people think the official advice on who and how many people you can meet is unclear. ${ }^{1}$ The survey, carried out between 17 and 29 July 2020, also reported that 56\% now believe that the government has not handled the pandemic well.

Speaking in the House of Commons on 8 September, health secretary Matt Hancock said, "We are seeing a concerning rise in the number of positive cases, particularly among younger people. These figures are a reminder that this virus is still with us and remains a threat.

"While young people are less likely to die from this disease, they are still at risk. The long term effects can be terrible and they can infect others. Six months on, many people are still suffering chronic fatigue, muscle pain, and breathing difficulties. Previously fit and healthy people have been reduced to being barely able to function.”

Hancock then used Spain and France as examples of where "a rise in cases, initially in younger people, then spreads, leading to hospitalisation and fatalities."

The following day (9 September), the government announced the new rules around gatherings, which give police the authority to break up groups larger than six and to impose fines on groups that fail to comply. A first offence will lead to a fine of $€ 100$ ( $€_{110}$; \$129), which will double with each further offence up to $€_{3200}$.

The government has also launched a new public information campaign called "Hands. Face. Space," which urges the public to wash their hands, cover their face, and social distance. The campaign will run across TV, radio, print, and digital display advertising.

Sian Griffiths, emeritus professor at the Chinese University of Hong Kong and past president of the Faculty of Public Health, said, "The UK figures appear to be several weeks behind those of France and Spain where the uptick in figures is beginning to be followed by an uptick in hospital admissions and deaths. Hopefully today's action will prompt all age groups to stop and think, and help to avoid further exponential rises and national lockdown."

Hancock told BBC's The Today Programme that the new restrictions will remain in place "for the foreseeable future," although he hoped "we can turn it around before Christmas."

1 Public perceptions of health and social care in light of covid-19. July 2020. www.health.org.uk/publications/reports/public-perceptions-of-health-and-socialcare-in-light-of-covid-19-july-2020. 